\title{
WILMS TUMOR IN ADULTS: CASE REPORT AND REVIEW OF THE LITERATURE
}

Bruno Rafael Kunz Bereza', Tariane Friedrich Foiato Maneti ${ }^{2}$, Vitor Arce Ferreira Cathcart ${ }^{3}$, Raimundo Romilton Leal do Rosário ${ }^{4}$, Paula Brandalise Nunes ${ }^{5}$, Murilo de Almeida Luz

'MD. Oncological surgeon at the Erasto Gaertner Hospital. Curitiba, Paraná, Brasil. brunobereza@hotmail.com ${ }^{2}$ Surgical Oncology Fellow at the Erasto Gaertner Hospital. Curitiba, Paraná, Brasil. tarianefoiato@msn.com ${ }^{3}$ Surgical Oncology Fellow at the Erasto Gaertner Hospital. Curitiba, Paraná, Brasil. vitoracf@me.com ${ }^{4}$ Surgical Oncology Fellow at the Erasto Gaertner Hospital. Curitiba, Paraná, Brasil. romilton08@gmail.com ${ }^{5}$ Medical intern in Oncology at the Erasto Gaertner Hospital. Curitiba, Paraná, Brasil. paula.b.nunes@uol.com.br •Urologic Oncologist. Surgical Oncology Residency Program Director at the Erasto Gaertner Hospital. Curitiba, Paraná, Brasil. muriloaluz@gmail.com

\begin{abstract}
Wilms Tumor (WT) is an extremely rare neoplasia in adults. It represents $95 \%$ and $1 \%$ of all renal tumors, in adults and children respectively. Clinical symptoms are also distinct between adults and children. In adults, symptoms are usually abdominal pain and hematuria, on the other hand, pediatric patients frequently present with an asymptomatic abdominal mass. The recommended treatment for WT in adults follows protocols established for pediatric patients. Currently, the 5-year overall survival rate for adults with WT is of approximately $90 \%$. The adoption of multimodal therapy systematized, and proposed by current protocols, allowed the results to become much more robust, with a significant improvement from less than $30 \%$ to $90 \%$. However, recent reviews suggest a worse outcome for adults when compared to children, even when submitted to the same treatment regimen, and comparable according to histology and tumor stage.
\end{abstract}

We present a case of a 26 years-old male patient, who underwent surgery to treat a solid renal mass. Pathological report demonstrated a Wilms tumor. The patiente also received adjuvant chemotherapy with dactinomycin and vincristine. After 12 months follow-up, patient has no evidence of disease.

Key Words: Wilms Tumor; Kidney Neoplasms; WT1 proteins; 
Wilms tumor (WT), also known as nephroblastoma, is an extremely rare tumor with few reports in the literature. Recent reviews mention a number of about 300 cases reported'. Although there is no difference of cause or histology for this tumor between adults or children, the symptomatology differs when these two groups are compared. WT is an embryogenic tumor, originated from nephrogenic blastemal cells, which replicates the histology of the kidneys and usually exhibits various patterns of differentiation.

Treatment is based on surgical resection of the mass, followed by the patient's risk classification and therefore definition for the use or not of adjuvant chemotherapy and, in some cases, radiation. However, protocols are lacking of standardization for unresectable diseases or inoperable relapses ${ }^{2}$.

Cancer control rates of WT are worse in adults when compared to children. The reason for this disparity are factors such as diagnosis in advanced stages, lack of the knowledge of the pathology by oncologists and pathologists, absence of standardized treatment protocols and delay of risk stratification to define adjuvant treatment ${ }^{3}$. Even when clinical stages are compared side by side, the prognosis is worse in adults.

\section{CASE REPORT}

Patient is 26 -year-old male who initially presented with macroscopic hematuria associated with left flank pain. Also, he had a feeling of abdominal mass on the left flank. He referred no weight loss. On physical examination, vital signs were normal and the general status of the patient was good, classified at the first clinical evaluation as Karnofsky of $80 \%$. During abdominal examination, patient felt pain and showed a $12 \mathrm{~cm}$ palpable hard mass in the upper left quadrant. He referred a family history of a daughter operated when she was 2 years old by adrenal tumor although there was no pathology report available. Patient was formerly a smoker with smoking history of 8 years, 1 pack of cigarettes per day and he quit smoking 1 year ago. Laboratory exams showed blood cells count and renal function were within normal ranges. An abdominal contrasted CT-scan showed an $18 \mathrm{~cm}$ well delimited left renal mass, no signs of extrarenal involvement (figure 1 and 2). Thus, patient underwent an open left radical nephrectomy with para-aortic lymphadenectomy through a subcostal incision. No gross lymph nodes were found, and no infiltration to adjacent organs. Histopathology diagnosed a malignant kidney tumor, undifferentiated small cell (figures 3 and 4), measuring $16 \mathrm{~cm}$. Twelve lymph nodes were dissected and all these were free of malignant cells. The immunohistochemistry study was positive for vimentin and WT-1 with Ki67 30\%, suggesting morphologic features of WT (figures 5 and 6). Patient had an uneventful outcome after surgery and was discharged on post-operative day 3 presenting normal renal function. Patient was then referred to adjuvant chemotherapy with dactinomycin and vincristine. After 12 months follow-up, patient is still free of disease.

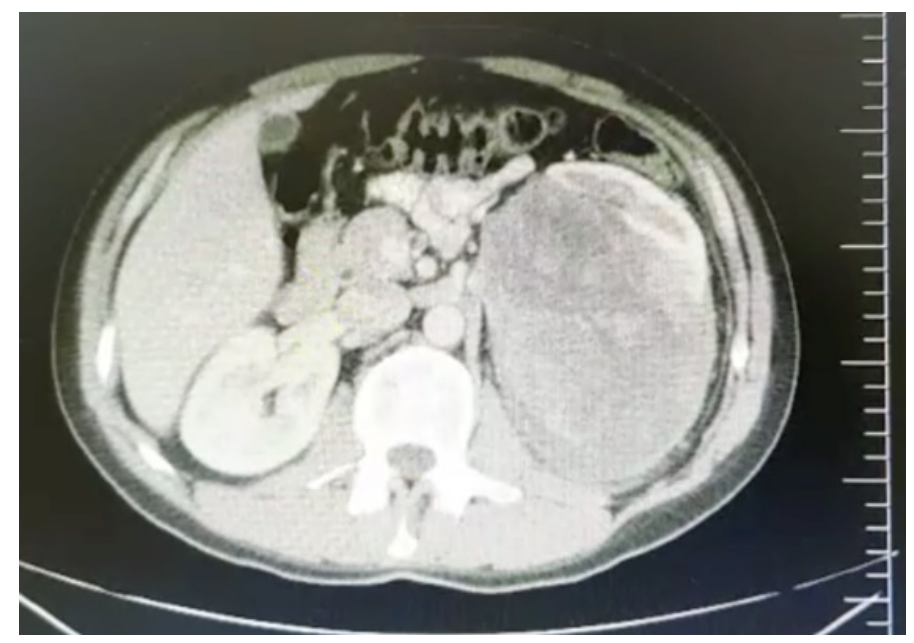

Figure 1. Abdominal CT-scan showing and extensive left renal mass. 


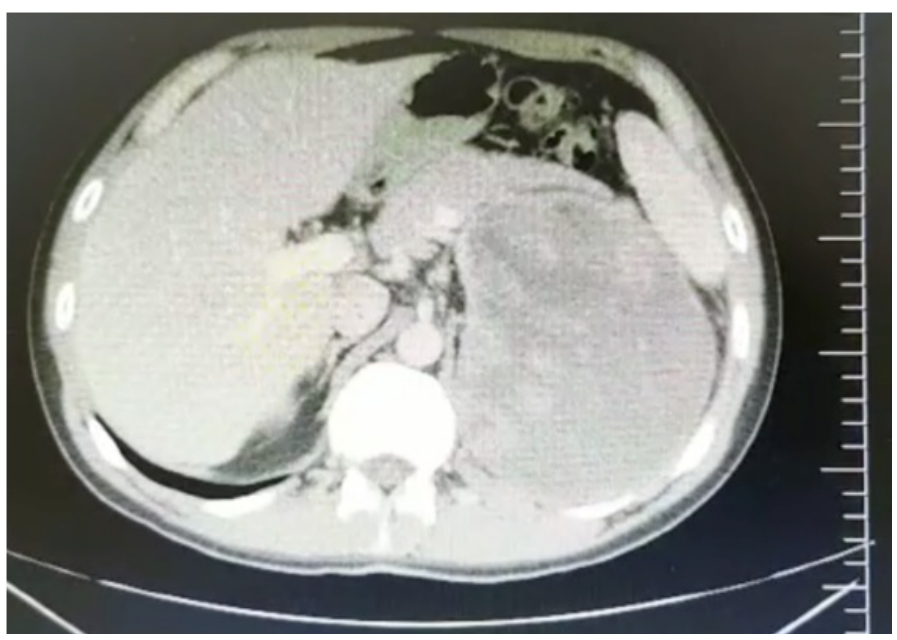

Figure 2. CT-scan - extensive left renal mass with no adjacente organ invasion.

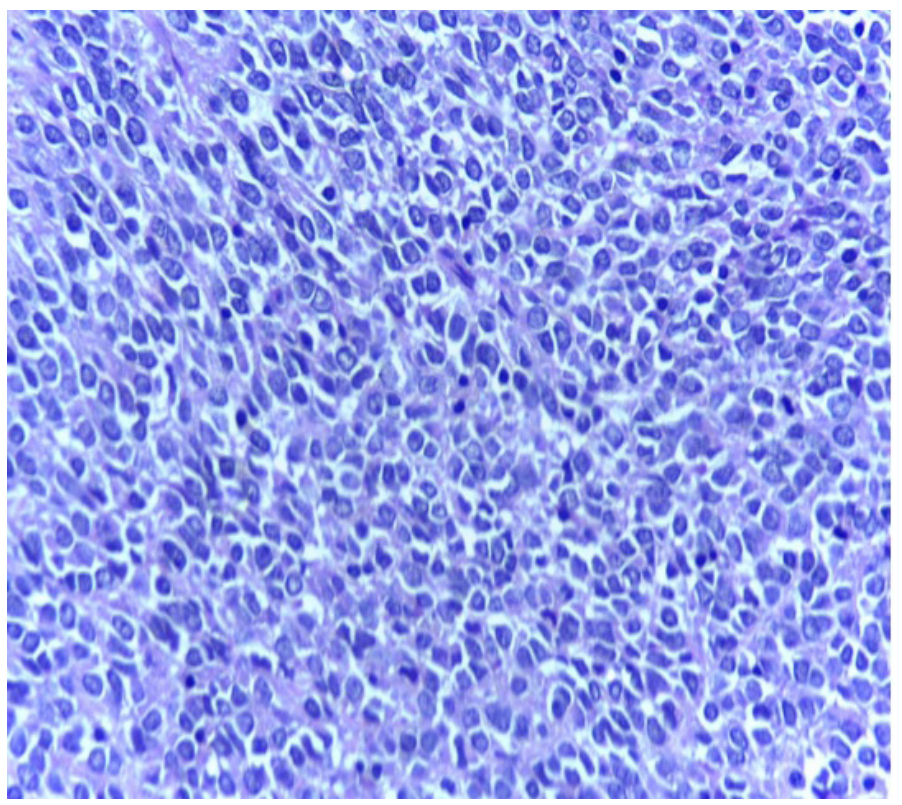

Figure 3. HE demonstrating and undifferentiated tumor with small blue cells.

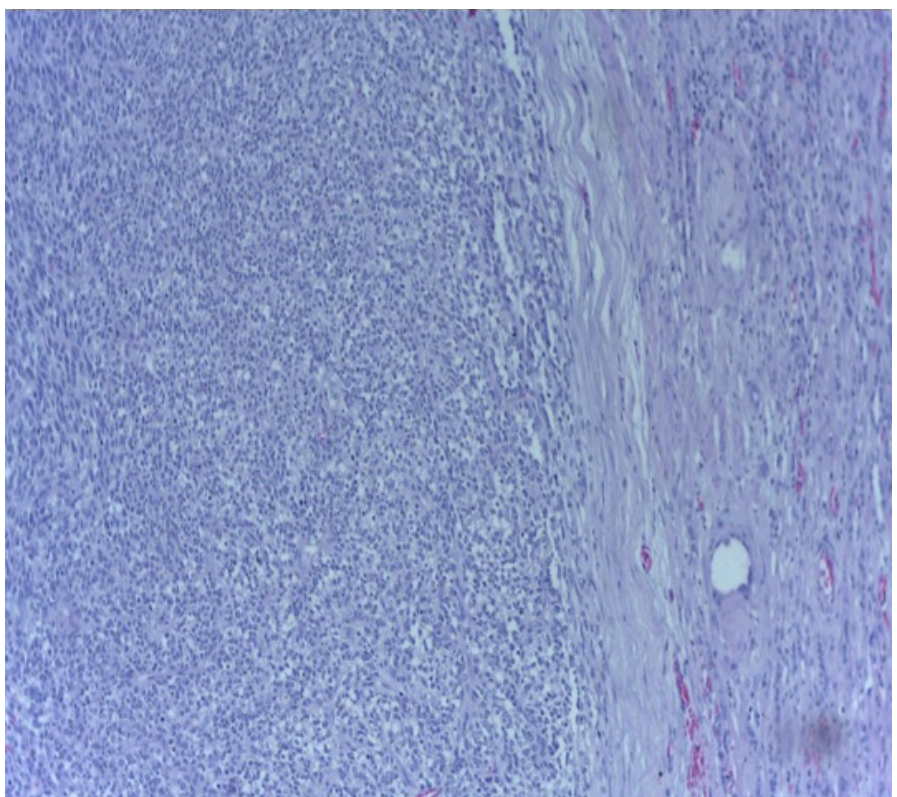

Figure 4. HE showing transition between tumor cells and normal kidney. 


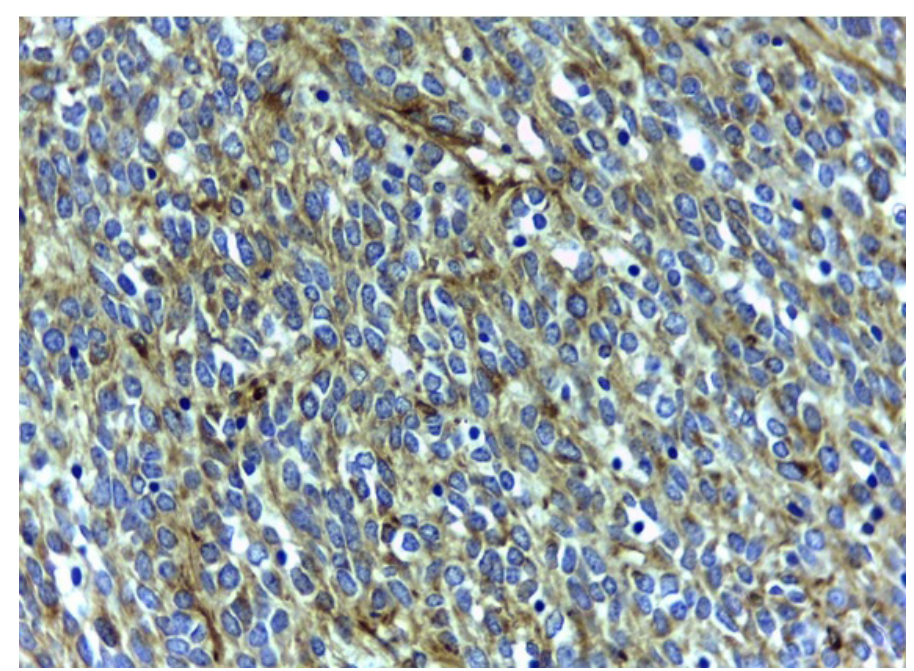

Figure 5. IHQ diffusely positive for WT-1 marker.

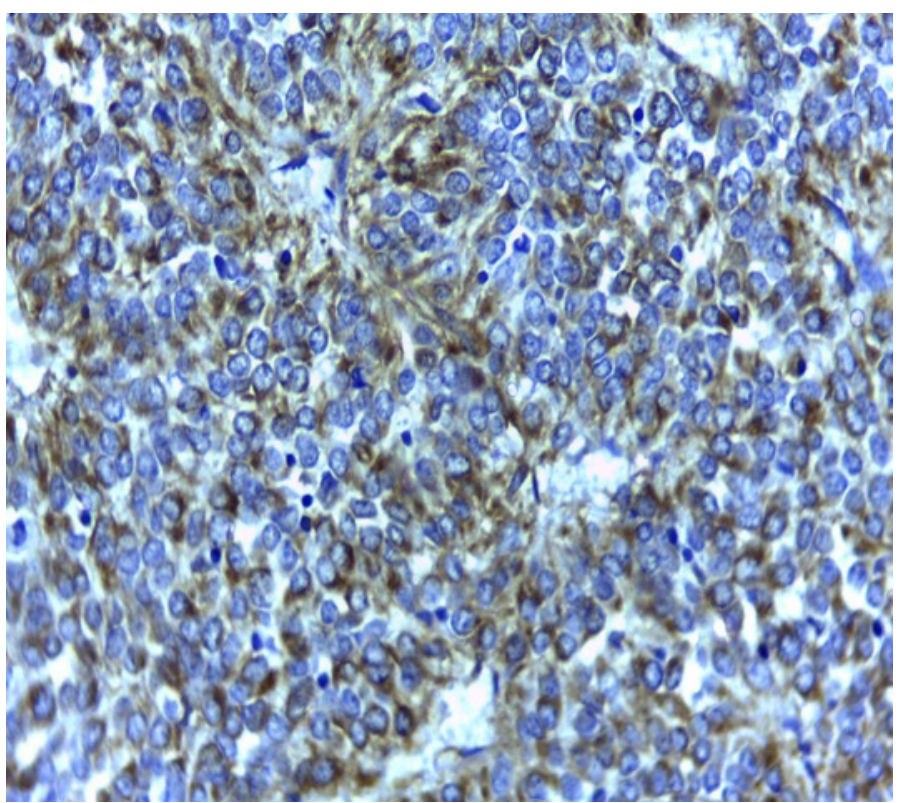

Figure 6. IHQ diffusely positive for Vimentin marker.

\section{DISCUSSION}

WT is an extremely rare neoplasia in adults. While in children it represents about $95 \%$ of renal neoplasms, 4 in adults it corresponds to less than $1 \%$ of all kidney cancers ${ }^{5}$.

The clinical presentation consists mainly of abdominal or flank pain, weight loss, anorexia and a deterioration in status performance ${ }^{6}$; on the other hand, pediatric patients frequently present with an asymptomatic abdominal mass ${ }^{7}$. In the majority of cases, the clinical scenario and imaging tests cannot distinguish between WT and other renal neoplasms, and mainly tumor final diagnosis is only achieved by pathological analysis ${ }^{6}$. Usually the diagnosis is only made after nephrectomy on suspicion of clear cell carcinoma, the most common kidney tumor in adults. At diagnosis, adults have more advanced disease ${ }^{6}$, $50 \%$ of them already presenting stages III and IV ${ }^{8}$ as well as more metastases at diagnosis, especially to the lungs ${ }^{6,9}$, when compared to children. Kilton et $\mathrm{al}^{10}$, made criteria for diagnosis of adult Wilms' tumour: (a) It should be a primary renal neoplasm (b) 
There should be presence of primitive blastematous spindle or round cell component (c) It has the mandatory formation of abortive or embryonal tubular or glomeruloid structures (d) No area of the tumour should show features of renal cell carcinoma (e) Pictorial confirmation of histology is required (f) Age must be more than 15 years.

Macroscopically, WT usually presents as a spherical mass on the periphery or central area of the kidney, with a soft consistency and usually gray or brown in color. There may be areas of hemorrhage or necrosis ${ }^{11}$. Classic WT has a triphasic appearance, with varying proportions of three cell types (blastemal, stromal and epithelial). The neoplasm may show extreme histological diversity, which may lead to diagnostic difficulties and final characterization may be challenging. The main microscopic pathology finding is the presence of small round cell tumors with high nucleus/cytoplasm ratio and may be present rosettes. Pathology may show nephrogenic rests in approximately $25-40 \%$ cases $^{12}$. Immunohistochemistry may be essential in the differentiation of WT, which is WT1 positive and rarely positive for $C D 99$, this one a very important piece of information to differentiate WT from PNET neoplasms. The blastemal component (cell compact areas) of WT consisted of vimentin-positive cells ${ }^{13}$.

Genetically, many genes have been implicated in the development of WT, among them: WT 1 (11p13), WT2 (11p15) and abnormalities in 16p, $1 p$ and $17 p$. Mutations of the p53 tumor suppressor gene may also be present in WT anaplastic forms ${ }^{14}$. The pathological assessment provides essential information to determine prognosis. Factors that need to be evaluated are capsular invasion, renal vein invasion, resection margins, lymph node status and renal sinus involvement including venous and lymphatic invasion in the sinus ${ }^{11}$.

The recommended treatment for WT in adults follows protocols established for pediatric patients by the National Wilms Tumor Study Group (NWTS) and Societe Internationale D'oncologie pédiatrique (SIOP). The treatment consists of radical nephrectomy followed by systemic chemotherapy. Radiotherapy should be performed in stages III and IV, on renal bed and metastases sites when needed ${ }^{6,15}$. The toxicity related to chemotherapy appears to be greater in adults, mainly associated with vincristine and dactinomycin ${ }^{6,9}$. To try to avoid toxicity, it is suggested that, in adults, the dose adjustment should be made in accordance with the body surface area and not to the body weight, like it is done in children patients?

Currently, 5-year survival rates in adults with WT is approximately $90 \% \%^{6}$. This large improvement is due to the adoption of systematized multimodal therapy proposed by protocols and advances in surgical techniques. Also, the effectiveness of chemotherapeutic agents and radiotherapy allowed the results to become as satisfactory as those observed in children, when exposed to the same treatment regimen, with similar histology and tumor stage $e^{6,16}$.

\section{CONCLUSION}

WT in adults is uncommon. Due to the rarity of the disease in the adult population, the diagnosis is challenging, mainly requiring immunohistochemistry for the differentiation from other renal neoplasms. There is no specific treatment protocol for this pathology in adults, and management follows the same steps as for the pediatric group.

\section{ACKNOWLEDGEMENTS}

The authors participated in the design and planning of the research project; obtaining and analyzing data; the writing and critical review of the article. We thank Sérgio Ossamu loshii M.D. and Juliana Elizabeth Jung M.D., from pathologic anatomy department of the Erasto Gaertner Hospital, for their contribuition.

\section{COMPETING INTERESTS}

No financial, legal or political competing interests with third parties (government, commercial, private foundation, etc.) were disclosed for any aspect of the submitted work (including but not limited to grants, data monitoring board, study design, manuscript preparation, statistical analysis, etc.). 


\section{REFERENCES}

1. Modi S, Tiang KW, Inglis P, Collins S. Adult Wilms' Tumour: Case Report and Review of Literature. Journal of Kidney Cancer and VHL. 2016;3(2):1-7. doi: 10.15586/ ikcvhl.2016.52

2. Provenzi M, Saettini F, Conter V, Chinaglia D, Vai $P$, Bruno $A$ et al. Is there a role for FDG-PET for the assessment of treatment efficacy in Wilms' tumor? A case report and literature review. Pediatr Hematol Oncol. 2013;30(7):633639. doi: $10.3109 / 08880018.2013 .832446$

3. Morabito V, Guglielmo N, Melandro F, Mazzesi G, Alesini F, Bosco $S$ et al. Adult Wilms tumor: case report. Int J Surg Case Rep. 2015;6:273-6. doi: 10.1016/i.ijscr.2014.06.021

4. Bernstein $L$, Linet $M$, Smith MA et al. Cancer incidence and survival among children and adolescents: United States SEER Program 1975-1995. National Cancer Institute; 1999. p.79.

5. Segers $H$, van den Heuvel-Eibrink MM, Pritchard-Jones $K$, Coppes MJ, Aitchison M, Bergeron C et al. SIOP-RTSG and the COG-Renal Tumor Committee. Management of adults with Wilms' tumor: recommendations based on international consensus. Expert Rev Anticancer Ther. 2011 ; 11 (7): 1 105-13. doi: $10.1586 /$ era.11.76

6. Reinhard H, Aliani S, Ruebe C, Stöckle M, Leuschner I, Graf N. Wilms' tumor in adults: Results of the Society of Pediatric Oncology (SIOP) 93-01/society for Pediatric Oncology and Hematology (GPOH) study. J Clin Oncol. 2004;22(22):4500-6. doi: 10.1200/JCO.2004.12.099

7. Fernandez C, Geller JI, Ehrlich PF et al. Renal tumors. In: Principles and Practice of Pediatric Oncology, 6th ed, Pizzo P, Poplack D (Eds), Lippincott Williams \& Wilkins, St. Lovis; 2011 . p. 861.

8. Geethamani V, Kusuma V, Gowda KM, Saini ML. Adult Wilms' tumor: A case report with review of literature. Diagn Pathol. 2006; 1:46. doi: 10.1186/1746-1596-1-46

9. Wadhwa N, Mishra K, Agarwal S. Wilms' tumor in adults: A report of three cases. Indian J Pathol Microbiol. $2005 ; 48(2): 235-8$.

10. Kilton L, Mathews MJ, Cohen MH. Adult Wilms' tumour: a report of prolonged survival and review of literature. J Urol. $1980 ; 124(1): 1-5$.

11. Govender D. The pathology of nephroblastoma. Diagnostic Pathology. 2000;6(1):45-54. doi: 10.1054/ cdip.2000.0012

12. Patnaik N, Mishra K, Saini P, Agarwal N. Primitive neuroec- todermal tumor of the kidney in a young male: Case report and review of literature. Urol Ann. 2015;7(2):236-239. doi: 10.4103/0974-7796.150537
13. Droz D, Rousseau-Merck MF, Jaubert F, Diebold N, Nezelof C, Adafer E et al. Cell differentiation in Wilms' tumor (nephroblastoma): an immunohistochemical study. Hum Pathol. 1990;21(5):536-44.

14. Arul GS. Nephroblastoma (Wilms' tumour), Surgery (Oxford). 2007;25(7):312-315.

15. Kalapurakal JA, Nan $B$, Norkool $P$, Coppes $M$, Perlman E, Beckwith B, Ritchey M, Breslow, N, Grundy P, D'angio GJ, Green DM, Thomas PRM. Treatment outcomes in adults with favorable histologic type Wilms tumor-an update from the national Wilms tumor study group. International Journal of Radiation Oncology, Biology, Physics. 2004;60(5):13791384. doi: 10.1016/i.ijrobp.2004.05.057

16. Arrigo S, Beckwith JB, Sharples K, D'Anglo G, Haase $G$. Better survival after combined modality care for adults with Wilms' tumor. A report from the National Wilms' Tumor Study. Cancer. 1990;66(5):827-830. doi: 10.1002/10970142(19900901)66:5 